\title{
NILAI-NILAI RELIGIUS DALAM SYAIR SHALAWAT BURDAH
}

\author{
Eko Setiawan
}

Email: oke.setia@gmail.com

Program Pascasarjana Sosiologi Universitas Brawijaya Malang

Alamat Korespondensi: Bangurejo RT 04 RW 03 Bangorejo Banyuwangi Jawa Timur

\begin{abstract}
Shalawat Burdah is poetic expression of love Imam Bushiri to Prophet Muhammad SAW. Moral values contained in the blessings Burdah among others about taubat, zuhud, patience, sincerity, tawakal, mahabbah. Shalawat Burdah meets the characteristics of the propagation of Islam: first, the art of worship and blessings clearly contain beads, because it contains the teachings of Islam about the blessings of the Prophet Muhammad Saw and the lyrics are loaded with rosary to God. Second, the real blessings containing shades of coolness and a reflection of the religious attitude of a person or a group. The art of giving identity blessings upon the lives of the Muslims can be seen and felt by others.
\end{abstract}

Keywords: Values, Religious, Lyric, Shalawat Burdah

\section{PENDAHULUAN}

Sastra lisan merupakan sastra yang penyampaiannya secara lisan dari mulut seorang pencerita kepada sekelompok pendengar. Sastra lisan memberikan nilai-nilai positif kepada pendengarnya. Pesan yang terkandung di dalamnya memang menghendaki olah pikir untuk memahaminya. Bahasa kias yang digunakan begitu halus. Penyampaiannya terasa sederhana tetapi memiliki falsafah yang tinggi (Admazaki, 2005 , h. 134). Sastra lisan adalah bentuk karya sastra yang dilahirkan oleh masyarakat yang penyebaran atau pewarisannya dilakukan dengan lisan. Oleh karena itu sastra lisan tidak bisa dipisahkan dari lingkungan penceritaan, penyebaran dan masyarakatnya sendiri.

Dapat diketahui bahwa sastra lisan adalah suatu bentuk karya sastra yang dihasilkan oleh suatu masyarakat berdasarkan proses kreatif. Di dalamnya terdapat nilai dan norma kehidupan yang disampaikan secara lisan dengan bahasa sebagai medianya. Sastra lisan pada dasarnya berfungsi untuk menata kehidupan yang terkandung dalam masyarakat. Nilai kehidupan yang terkandung dalam sastra lisan tersebut seperti nilai-nilai sosial, agama dan budaya. Nilai adalah suatu perangkat keyakinan ataupun perasaan yang diyakini sebagai suatu identitas yang memberikan corak yang khusus kepada pola pemikiran, perasaan, keterikatan, maupun perilaku. (Darajad, 1984, h. 260).

Kasidah burdah merupakan pelopor yang menghidupkan kembali penyusunan syair-syair pepujian kepada Nabi Muhammad SAW. Ia adalah syair al-mada'ih anNabawiyyah paling awal pasca terjadinya kekosongan yang sangat panjang. Barulah syair-syair al-mada'ih lainnya muncul setelahnya. Burdah adalah syair mada'ih (pujipujian) kepada Rasulullah SAW, yang ditulis oleh Imam Bushiri. Beliau mengungkapkan perasaan cinta dan rindu kepada Rasulullah SAW, lewat syair-syairnya yang berjudul "alkawakib al-durriyah fi madh khayr albariyyah" (bintang kemilau dalam memuji makhluk terbaik) yang kemudian terkenal dengan qasidah al- burdah. Syair ini termasuk kekayaan kesustraan Arab yang memiliki pola sejati dan sempurna dalam memuji Rasulullah SAW. Di dalamnya berisi mutiara pelajaran yang lengkap tentang sikap hormat di hadapan makhluk pilihan dan kekasih Tuhan seluruh alam. 
Keindahan susunan bahasanya yang teratur membuat syair yang menggunakan akhiran mimiyat ini mudah dihafal. Selain itu burdah juga dapat dibaca dengan berbagai lagu. Sehingga burdah menjadi satu-satunya puisi kesusastraan bahasa Arab yang paling kuat bertahan. Banyak para sastrawan tertarik pada keindahan bahasanya terutama dalam mathla' (awal bait kasidah burdah). Pernah sebagian sastrawan ada yang mencoba menirukan syair burdah yang ternyata sulit ditirukan. Dalam ilmu sastra kepiawaian seorang penyair diukur dengan keindahan awal dari syair (syakwa al-gharam) yang disusunnya (Adib, 2009, h. 33). Dr. Zaki Mubarok, kritikus sastra Arab yang semula menganggap remeh burdah, ternyata berbalik mengakui nilai-nilai estetika yang amat tinggi pada karya Imam Bushiri. Bahkan De Tascy, pengamat sastra Arab dari Universitas Sorbonne Prancis, yang pertama kali menerjemahkan burdah dalam bahasa Prancis, menyatakan sampai saat ini belum ada penyair kontemporer Arab yang dapat menirukan kasidah burdah (Baharun, 1996, h. 19).

Sebagai syair cinta Rasul, sudah jelas bahwa yang dibicarakan adalah sosok Rasulullah SAW, yang tidak asing lagi bagi kita semua. Beliau adalah Nabi terakhir sekaligus sulthan al-anbiya' wa al-mursaliin. Kekaguman yang diungkapkan dalam kasidah burdah, merupakan apresiasi terhadap sosok Muhammad SAW, yang begitu besar pengaruhnya bagi umat manusia. Beliau adalah sebaik-baiknya ciptaan, manusia yang paling baik akhlaknya, berbudi pekerti halus, santun.

Kasidah burdah juga merupakan cermin perjalanan hidup Imam Bushiri sebagai seorang sufi (ahli tasawuf). Beliau penganut tarekat sadziliyah, yaitu tarekat yang didirikan oleh Syekh Abu Hasan asy-Syadzili. Allah SWT menganugrahi perasaan cinta kasih dan rindu kepada Rasul Nya ke dalam lubuk hati beliau, yang kemudian beliau ungkapkan lewat shalawat burdah. Dengan cintanya al-Bushiri kepada Rasulullah SAW, Allah SWT menunjukkan cinta Nya terhadap Rasulullah sebagai al-habib al-mushthafa (kekasih pilihan). Makna itulah yang hendak disampaikan oleh al-Bushiri dalam puisi-puisi cintanya. Selain itu di dalam cinta dan diri tersebar pandangan dunia dan kerohanian seorang penyair yang sebenarnya. Cinta dipandang penting dan dijadikan tumpuan oleh banyak penyair muslim khususnya oleh penulis-penulis sufistik, karena seperti yang dikatakan Rumi, "cinta adalah lautan tanpa tepi, cinta adalah alat penangkap rahasiarahasia ketuhanan".

Di Indonesia sendiri burdah sudah sangat populer. Hal ini disebabkan burdah merupakan salah satu kitab-kitab maulid yang sering dibaca pada peringatan maulid Nabi Muhammad SAW. Sedangkan peringatan maulid Nabi Muhammad SAW, di Indonesia sudah menjadi tradisi bagi masyarakat pada umumnya. Diketahui bahwa tradisi peringatan maulid Nabi Muhammad SAW, sudah ada di Indonesia sejak abad ke13 dan ke 16, pada awal perkembangan Islam di nusantara. Maulid burdah juga disebut shalawat, karena dalam pembacaannya wajib disahuti dengan bacaan shalawat. Islam mengategorikan shalawat sebagai salah satu ibadah sunnah yang diutamakan. Ada janji pahala yang sangat tinggi bagi orang-orang yang melakukannya. Firman Allah SWT:

Sesungguhnya Allah dan malaikat-malaikatNya bershalawat untuk Nabi. Hai orang-orang yang beriman, bershalawatlah kamu untuk Nabi dan ucapkanlah salam penghormatan kepadanya. (QS. Al-Ahzab: 56)

Shalawat juga dapat dijadikan wasilah mendekatkan diri kepada Allah. yaitu jalan tercepat menuju whusul kepada Allah adalah memperbanyak istighfar dan membaca salawat kepada Nabi Muhammad SAW. Kaitannya dengan wasilah untuk mendekatkan diri kepada Allah, dalam dunia tasawuf dikenal dengan tarekat. Ketika syair burdah dilantunkan, para jamaah larut dalam puisi madah Imam Bushiri ini. Seperti menghadirkan insan yang tersanjung itu, dengan penuh sikap hormat, cinta, rindu, dan pengharapan menyambut kedatangan kekasih yang ditunggu. Seorang yang tinggi derajatnya, mulia akhlaknya, lembut tutur katanya, penerang hati yang gelap, makhluk pilihan dan kekasih Tuhan seluruh alam. Dari berbagai definisi tersebut, dapat diperoleh pengertian bahwa shalawat merupakan bentuk puji-pujian yang ditujukan kepada Nabi Muhammad SAW. Bentuk dan ragam shalawat beraneka macam salah satunya yakni shalawat burdah yang merupakan syair puji-pujian yang dikarang oleh seorang 
penyair bernama Abu Abdillah Syarafudin Abi Abdillah Muhammad bin Khamad ad-Dhalashi ash-Shanja asy-Syadzili al-Bushiri yang kemudian di kenal sebagai Imam Bushiri yang paling fenomenal di antara karya-karya yang lain, dan juga karena kasidah tersebut merupakan salah satu karya sastra yang paling populer dalam khazanah sastra Islam.

\section{Pengertian Shalawat Burdah}

Burdah artinya adalah jubah dari kulit atau bulu binatang. Pada awalnya burdah tidak memiliki muatan nilai historis apa-apa selain sebutan bagi baju hangat atau jubah sederhana yang biasa dipakai oleh orangorang Arab. Muatan nilai sakral baru muncul ketika pada suatu hari Nabi Muhammad SAW menghadiahkan baju burdah yang biasa beliau pakai kepada Kaab Ibn Zuhair $(662$ M) seorang penyair kenamaan yang baru saja masuk Islam sebagai penghargaan atas syair gubahannya yang berisi penghormatan dan sanjungan terhadap Nabi Muhammad SAW dan agama Islam yang dibawanya (Adib, 2009, h. 23). Burdah adalah syair puji-pujian (madaih) terhadap Rasulullah SAW yang ditulis oleh Imam Bushiri, sebagai ungkapan rasa rindu dan cinta yang dalam terhadap Nabi Muhammad SAW dengan segala implikasinya (Poerwadarminta, 2007, h. 195).

Berdasarkan pendapat yang lain, kata burdah sebenarnya memiliki arti berupa mantel dari wol yang dapat dipakai sebagai jubah diwaktu siang dan dipakai sebagai selimut di malam hari ( Baharun, 1996, h. 11). Shalawat Burdah merupakan syair puji-pujian yang ditujukan untuk Nabi Muhammad SAW, yang ditulis oleh seorang penyair bernama Abu Abdillah Syarafudin Abi Abdillah Muhammad bin Khammad ad-Dalashi ash Sanhaji asy-Syadzili Al Bushiri yang kemudian terkenal sebagai Imam Bushiri. Mengapa shalawat ini dinamakan sebagai shalawat burdah? Berdasarkan cerita Bushiri sendiri konon ketika ia sedang menderita kelumpuhan akibat penyakit yang bernama angin merah, dalam mimpinya ia bertemu dengan Rasulullah SAW dan kemudian Rasul memberikan mantel (burdah) itu kepadanya. Yakni mantel yang sama seperti yang diberikan Kaab, ia terkejut dan melompat dari tidurnya sehingga lumpuhnya tak terasa lagi. Begitu bangun ia merasa terharu sekali lalu menulis syair-syair yang dikenal dengan judul al-kawakib ad durriyah (bintang-bintang gemerlapan). Syair tersebut berisi puji-pujian terhadap Nabi. Dan karena ada hubungannya dengan mantel yang diberikan oleh Nabi, maka kemudian syair-syair tersebut dikenal dengan nama al-burdah. Burdah terdiri dari 160 bait, yang berisi nasehat dan peringatan. upamanya soal angkara nafsu, pujian kepada Nabi, keagungan Al-Quran, Isra Miraj, jihad prajurit Nabi Muhammad SAW, doa-doa (munajat-munajat) serta shalawat kepada Nabi, keluarga, para sahabat.

\section{Biografi Pengarang Shalawat Burdah}

Imam Bushiri juga disebut-sebut berdarah Maroko dari marga Bani Habnun. Ibunya berasal dari Bushir, sedangkan nenek moyangnya dari garis ayah tinggal di Dalash. Oleh karena itu, kadang ia di sebut Al-Bushiri, kadang Ad-Dalashi, kadang Ad-Dalashiri gabungan dari Dalashi dan Bushiri. Awal studinya dimulai dengan menghafal Al-Quran, lalu ke Kairo bergabung dengan para pelajar yang menuntut ilmu di Masjid Syekh Abd AzZahir. di situ Al-Bushiri belajar berbagai macam ilmu agama, juga ilmu bahasa dan sastra. Kairo merupakan kota yang menjadi tempat tinggal Bushiri dalam masa yang panjang dalam hidupnya.

Pada tahun $1250 \mathrm{M}$, di saat berusia sekitar 40 tahun, Imam Bushiri mulai mempelajari dan menekuni ilmu-ilmu tasawuf. Jalur yang dia pilih adalah tasawuf melalui amalan-amalan dan tarekat syadziliyyah. Sebuah tarekat rintisan seorang sufi kebangsaan Tunisia yang bernama Abu Al-Hasan Asy-Syadzili. Tarekat ini ia tekuni di bawah bimbingan Abu Al-Abbas Al-Mursi, salah seorang murid senior Asy- Syadzili. Ternyata pada tahapan kehidupan selanjutnya, ajaran tasawuf yang ditekuninya itu berpengaruh cukup besar terhadap pola pemikiran dan orientasi karya sastranya (Adib, 2009, h. 13).

Imam Bushiri merupakan penyair yang sangat produktif. Banyak karya sastra terutama syair yang telah digubahnya. Selain produktif dia juga sangat mumpuni kemampuan sastranya, terbukti syair gubahannya diakui memiliki nilai sastra yang sangat tinggi. Burdah merupakan karya yang paling fenomenal dari Imam Bushiri, dibanding karya-karyanya yang lain. Sejak awal syair burdah sudah mendapatkan 
perhatian yang besar dari masyarakat luas. Baik kalangan awam maupun budayawan. Di kawasan Eropa pun tidak kurang dari enam edisi terjemahan shalawat burdah telah diterbitkan. Antara lain, Uri (1861) seorang sastrawan asal Belanda, orang pertama yang menerjemahkan syair-syair burdah ke dalam bahasa Latin dengan judul Carmen Mysticum Borda Dictum. Terjemahan ini dicetak berulang-ulang dan tersebar luas terutama di Leiden Belanda. Di Jerman, setidaknya ada dua edisi terjemahan yang diterbitkan. Yang pertama diterjemahkan oleh Von Rosenweg (1824) dengan judul Funkelnde Vandelsterne Zum Iobe Des Geschopfe, sementara yang kedua oleh Redhouse (1881) dengan judul The Burda, sementara di Italia, ada satu edisi yang berhasil ditemukan yaitu terjemahan Gabrielli (1901) dengan judul Al-Burdatain (Adib, 2009, h. 27).

Setelah mengarungi kehidupan selama sekitar 82 tahun, pada penghujung abad ke 13 M, tepatnya pada 1295, Imam Bushiri menghembuskan nafas terakhirnya dengan tenang di Iskandaria. Konon jenazahnya dikebumikan di dekat bukit Al-Mughatham berdekatan dengan makam Muhammad Ibn Idris Asy-Safii tokoh sentral Mazhab Syafi'i (Adib, 2009, h. 19).

\section{Isi Kandungan Shalawat Burdah}

Bait-bait shalawat burdah terdiri dari sepuluh tema pokok pembicaraan, yaitu, (1) Prolog cinta sang kekasih, berjumlah12 bait (2) Peringatan akan bahaya menuruti hawa nafsu, sebanyak 16 bait (3) Pepujian, sebanyak 30 bait (4) Kisah kelahiran, sebanyak 13 bait (5) Mukjizat, sebanyak16 bait (6) Al-Quran, sebanyak 17 bait (7) Isra Miraj, sebanyak 13 bait (8) Jihad, sebanyak 12 bait (9) penutup dan permohonan ampun, sebanyak 12 bait dan ada yang berpendapat sebanyak 19 bait. Berikut ini adalah arti dari shalawat burdah sesuai dengan tema masingmasing:

\section{Bagian 1) Cinta Sang Kekasih}

Apakah karena mengingat para kekasih di Dzi Salam. Kau campurkan air mata di pipimu dengan darah. Ataukah karena angin berhembus dari arah Kazhimah. Dan kilat berkilau di lembah Idlam dalam gulita malam. Mengapa bila kau tahan air matamu ia tetap basah. Mengapa bila kau sadarkan hatimu ia tetap gelisah. Apakah sang kekasih kira bahwa tersembunyi cintanya. Diantara air mata yang mengucur dan hati yang bergelora. Jika bukan karena cinta takkan kau tangisi puing rumahnya. Takkan kau bergadang untuk ingat pohon ban dan alam. Dapatkah kau pungkiri cinta, sedang air mata dan derita. Telah bersaksi atas cintamu dengan jujur tanpa dusta. Kesedihanmu timbulkan dua garis tangis dan kurus lemah. Bagaikan bunga kuning di kedua pipi dan mawar merah. Memang terlintas dirinya dalam mimpi hingga kuterjaga. Tak hentinya cinta merindangi kenikmatan dengan derita. Maafku untukmu wahai para pencaci gelora cintaku. Seandainya kau bersikap adil takkan kau cela aku. Kini kau tahu keadaanku, pendusta pun tahu rahasiaku. Padahal tidak juga kunjung sembuh penyakitku. Begitu tulus nasihatmu tapi tak kudengar semuanya. Karena untuk para pencaci, sang pecinta tuli telinganya. Aku kira ubanku pun turut mencelaku. Padahal ubanku pastilah tulus memperingatkanku.

\section{(Bagian 2) Peringatan Akan Bahaya Hawa Nafsu}

Sungguh hawa nafsuku tetap bebal tak tersadarkan. Sebab tak mau tahu peringatan uban dan kerentaan. Tidak pula bersiap dengan amal baik untuk menjamu. Sang uban yang bertamu di kepalaku tanpa malu-malu. Jika kutahu ku tak menghormati uban yang bertamu. Kan ku sembunyikan dengan semir rahasia ketuaanku itu. Siapakah yang mengembalikan nafsuku dari kesesatan. Sebagaimana kuda liar dikendalikan dengan tali kekang. Jangan kau tundukkan nafsumu dengan maksiat. Sebab makanan justru perkuat nafsu si rakus pelahap. Nafsu bagai bayi, bila kau biarkan akan tetap menyusu. Bila kau sapih ia akan tinggalkan menyusu itu. Maka kendalikan nafsumu, jangan biarkan ia berkuasa. Jika kuasa ia akan membunuhmu dan membuatmu celaka gembalakanlah ia, ia bagai ternak dalam amal budi. Janganlah kau giring ke ladang yang ia sukai. Kerap ia goda manusia dengan kelezatan yang mematikan. Tanpa ia tahu racun justru ada dalam lezatnya makanan. Kumohon ampunan Allah karena bicara tanpa berbuat. Kusamakan itu dengan keturunan bagi orang mandul. Kuperintahkan engkau suatu kebaikan yang tak kulakukan. Tidak lurus diriku maka tak guna kusuruh kau lurus. Aku tak berbekal untuk matiku dengan 
ibadah sunnah. Tiada aku dan puasa kecuali hanya yang wajib saja.

\section{(Bagian 3) Pujian Kepada Nabi Muhammad SAW}

Kutinggalkan sunnah Nabi yang sepanjang malam. Beribadah hingga kedua kakinya bengkak dan keram. Nabi yang karena lapar mengikat pusarnya dengan batu. Dan dengan batu mengganjal perutnya yang halus itu. Kendati gunung emas menjulang menawarkan dirinya. la tolak permintaan itu dengan perasaan bangga. Butuh harta namun menolak, maka tambah kezuhudannya. Kendati butuh pada harta tidaklah merusak kesuciannya. Bagaimana mungkin Nabi butuh pada dunia. Padahal tanpa dirinya dunia takkan pernah ada. Muhammadlah pemimpin dunia akhirat. Pemimpin jin dan manusia, bangsa Arab dan non Arab. Nabilah pengatur kebaikan pencegah mungkar. Tak satu pun setegas ia dalam berkata ya atau tidak. Dialah kekasih Allah yang syafaatnya diharap. Dari tiap ketakutan dan bahaya yang datang menyergap. Dia mengajak kepada agama Allah yang lurus. Mengikutinya berarti berpegang pada tali yang tak terputus. Dia mengungguli para Nabi dalam budi dan rupa. Tak sanggup mereka menyamai ilmu dan kemuliaannya. Para Nabi semua meminta dari dirinya. Seciduk lautan kemuliaannya dan setitik hujan ilmunya. Para Rasul sama berdiri di puncak mereka. Mengharap setitik ilmu atau seonggok hikmahnya. Dialah Rasul yang sempurna batin dan lahirnya. Terpilih sebagai kekasih Allah pencipta manusia. Dalam kebaikanya, tak seorang pun menyaingi. Inti keindahannya takkan bisa terbagi-bagi. Jauhkan baginya yang dikatakan nasrani pada Nabinya. Tetapkan bagi Muhammad pujian apapun kau suka. Nisbatkan kepadanya segala kemuliaan sekehendakmu. Dan pada martabatnya segala keagungan yang kau mau. Karena keutamaannya sungguh tak terbatas. Hingga tak satupun mampu mengungkapkan dengan kata. Jika mukjizatnya menyamai keagungan dirinya. Niscaya hiduplah tulang belulang dengan disebut namanya. Tak pernah ia uji kita dengan yang tak diterima akal. Dari sangat cintanya, hingga tiada kita ragu dan bimbang. Seluruh makhluk sulit memahami hakikat Nabi. Dari dekat atau jauh, tak satu pun yang mengerti. Bagaikan matahari yang tampak kecil dari kejauhan. Padahal mata tak mampu melihatnya bila berdekatan. Bagaimana seseorang dapat ketahui hakikat Sang Nabi Padahal ia sudah puas bertemu dengannya dalam mimpi puncak pengetahuan tentangnya ialah bahwa ia manusia. Dan ia adalah sebaik baik seluruh ciptaan Allah Segala mukjizat para Rasul mulia sebelumnya. Hanyalah pancaran dari cahayanya kepada mereka. Dia matahari keutamaan dan para Nabi bintangnya. Bintang hanya pantulkan sinar mentari menerangi gulita. Alangkah mulia paras Nabi yang dihiasi pekerti. Yang memiliki keindahan dan bercirikan wajah berseri. Kemegahannya bak bunga, kemuliaannya bak purnama. Kedermawanannya bak lautan, kegairahannya bak sang waktu. la bagaikan dan memang tiada taranya dalam keagungan. Ketika berada di sekitar pembantunya dan di tengah pasukan. Bagai mutiara yang tersimpan dalam kerangnya. Dari kedua sumber, yaitu ucapan dan senyumannya. Tiada keharuman melebihi tanah yang mengubur jasadnya. Beruntung orang yang menghirup dan mencium tanahnya.

\section{(Bagian 4) Kelahiran Sang Nabi SAW}

Kelahiran Sang Nabi menunjukkan kesucian dirinya. Alangkah eloknya permulaan dan penghabisannya. Lahir saat bangsa Persia berfirasat dan merasa. Peringatan akan datangnya bencana dan angkara murka. Dimalam gulita singgasana kaisar Persia hancur terbelah. Sebagaimana kesatuan para sahabat kaisar yang terpecah. Karena kesedihan yang sangat, api sesembahan padam. Sungai Eufrat pun tak mengalir dari duka yang dalam. Penduduk negeri sawah bersedih saat kering danaunya. Pengambil air kembali dengan kecewa ketika dahaga. Seakan sejuknya air terdapat dalam jilatan api. Seakan panasnya api terdapat dalam air, karena sedih tak terperi. Para jin berteriak sedang cahaya terang memancar. Kebenaran pun tampak dari makna kitab suci maupun terujar. Mereka buta dan tuli hingga kabar gembira tak didengarkan. Datangnya peringatan pun tak mereka hiraukan. Setelah para dukun memberi tahu mereka. Agama mereka yang sesat takkan bertahan lama. Setelah mereka saksikan kilatan api yang jatuh dilangit. Seiring dengan runtuhnya semua berhala dimuka bumi. Hingga lenyap dan pintu langit Nya. Satu demi satu setan lari 
tunggang langgang tak berdaya. Mereka berlarian laksana laskar Raja Abrahah. Atau bak pasukan yang dihujani kerikil oleh tangan Rasul. Batu yang Nabi lempar sesudah bertasbih digenggamannya. Bagaikan terlemparnya Nabi Yunus dari perut ikan paus.

\section{(Bagian 5) Mukjizat Nabi Muhammad SAW}

Pohon-pohon mendatangi seruannya dengan ketundukkan. Berjalan dengan batangnya dengan lurus dan sopan. Seakan batangnya torehkan sebuah tulisan. Tulisan yang indah di tengah-tengah jalan. Seperti juga awan gemawan yang mengikuti Nabi. Berjalan melindunginya dari sengatan panas siang hari. Aku bersumpah demi Allah pencipta rembulan. Sungguh hati Nabi bagai bulan dalam keterbelahan Gua Tsur penuh kebaikan dan kemuliaan. Sebab Nabi dan Abu Bakar di dalamnya, kaum kafir tak lihat mereka Nabi dan Abu Bakar Shiddiq aman didalamnya tak cedera. Kaum kafir mengatakan tak seorang pun didalam gua. Mereka mengira merpati takkan berputar diatasnya. Dan laba-laba takkan buat sarang jika Nabi didalamnya. Perlindungan Allah tak memerlukan berlapis baju besi. Juga tidak memerlukan benteng yang kokoh dan tinggi. Tiada satu pun menyakiti diriku, lalu kumohon bantuan Nabi. Niscaya kudapat pertolongannya tanpa sedikit pun disakiti. Tidaklah kucari kekayaan dunia akhirat dari kemurahan Nya. Melainkan kuperoleh sebaikbaik pemberian Nya. Janganlah kau pungkiri wahyu yang diraihnya lewat mimpi. Karena hatinya tetap terjaga meski dua matanya tidur terlena. Demikian itu tatkala sampai masa kenabiannya. Karenanya tidaklah diingkari masa mengalami mimpinya Maha Suci Allah, wahyu tidaklah bisa dicari. Dan tidaklah seorang Nabi dalam berita gaibnya dicurigai. Kerap sentuhannya sembuhkan penyakit. Dan lepaskan orang yang berhajat dari temali kegilaan. Doanya menyuburkan tahun kekeringan dan kelaparan. Bagai titik putih di masa-masa hitam kelam. Dengan awan yang curahkan hujan berlimpah. Atau kau kira itu air yang mengalir dari laut atau lembah.

\section{(Bagian 6) Kemulian Al-Qur'an dan pujian terhadapnya}

Biarkan kusebut beberapa mukjizat yang muncul pada Nabi. Seperti nampaknya api jamuan, malam hari diatas gunung tinggi. Mutiara bertambah indah bila ia tersusun rapi. Jika tak tersusun nilainya tak berkurang sama sekali. Segala pujian itu puncaknya adalah memuji. Sifat dan pekerti mulia yang ada pada Nabi. Ayat-ayat Al-Quran yang diturunkan Allah adalah baharu. Tapi Allah adalah kekal tak kenal waktu. Ayat-ayat yang tak terikat waktu dan kabarkan kita. Tentang hari kiamat, kaum Aad dan negeri Irom. Ayat-ayat yang selalu bersama kita dan mengungguli. Mukjizat para Nabi yang muncul tapi tak lestari. Penuh kepastian dan tak sisakan bagi para musuh segala keraguan. Ayat yang tak sedikit pun menyimpang dari kebenaran. Tak satu ayat pun ditentang kecuali musuh terberatnya. Akan kembali kepadanya dengan salam dan beriman. Keindahan sastranya membuat takluk penentangnya. Bak pencemburu membela kehormatan dari tangan pendosa. Baginya makna-makna yang saling menunjang bak ombak lautan. Yang nilai keindahannya melebihi mutiara berkilauan. Keajaibannya banyak dan tak terhingga. Dan keajaiban itu tak satu pun membuat bosan kita. Teduhlah mata pembacanya, lalu kukatakan padanya. Beruntunglah engkau, berpeganglah selalu pada tali Nya. Jika kau baca ia karena takut panas neraka lazha. Padamlah panas neraka lazha karena kesejukannya. Bagai telaga kautsar wajah pendosa jadi putih karenanya. Padahal dengan wajah hitam arang mereka datangi ia. la lurus bagai shirath, adil bagai timbangan. Kitab-kitab lain takkan selanggeng ia dalam keadilan. Jangan heran pada pendengkinya yang selalu ingkar. Pura-pura bodoh padahal ia cukup paham dan pintar. Bagai orang sakit mata yang pungkiri sinar mentari. Bagai orang sakit yang lezatnya air ia pungkiri.

\section{(Bagian 7) Isra Miraj Nabi Muhammad SAW}

Wahai manusia terbaik yang dituju pekarangannya. Dijalan atau menunggangi unta yang cepat larinya. Wahai Nabi yang jadi pertanda bagi pencari kebenaran. Yang jadi karunia terbesar bagi pencari nikmat Tuhan. Malam itu kau berjalan dari Masjidil Haram ke Al Aqsha. Bagai purnama yang bergerak di malam gulita. Kau terus saja meninggi hingga sampai tempat terdekat. Yang tak seorang pun mencapai atau mengharap. Para Nabi mendahulukanmu berdiri di depan. Tak 
ubahnya penghormatan pelayan kepada sang tuan. Kau terobos tujuh lapis langit bersama mereka. Dalam barisan para Malaikat kaulah pemimpin mereka. Hingga tak satu puncak pun tersisa bagi pengejarmu. Tak sederajat pun bagi pencari kemuliaan tersisa olehmu. Karena keluhuranmu, derajat menjadi rendah semua. Ketika kau diseru bagai pemimpin tunggal yang mulia. Agar kau peroleh hubungan khusus yang terselubungkan. Juga rahasia yang senantiasa tersimpan. Kau peroleh kebanggaan yang tak terbagi. Kau lewati setiap derajat tanpa seorang pun menyaingi. Sungguh agung derajat yang kau dapatkan. Sungguh jarang nikmat yang kepadamu telah diberikan. Kabar gembira wahai umat Islam bagi kita tiang kokoh. Yang dengan Inayah dari Allah, tak akan roboh. Ketika Allah juluki ia Rasul termulia karena sangat taat ia Rasul termulia maka jadilah kita sebaik baik umat.

\section{(Bagian 8) Jiwa Militan Rasulullah SAW}

Berita kenabian membuat musuh takut dan gundah. Bak lolongan serigala yang takutkan si kambing lengah. Tak henti ia lawan para musuh di medan pertempuran. Hingga mereka bagai daging terserak diatas meja jamuan. Mereka ingin lari dan mati saja bak kawan yang terkapar. Mati menggelepar dikoyak elang dan burung nasar. Siang malam berlalu tanpa mereka kenal waktu. Hingga tiba bulan terlarang ketika Nabi hentikan perang. Islam datang bagai tamu yang singgah di pekarangan. Yang sangat ingin membunuh musuh-musuh Islam. la bawa lautan pasukan diatas kuda yang meluncur. Membawa para gagah berani bagai ombak yang berdebur. Mereka pejuang yang mengharap syahid dan surga Allah. Menyerang untuk membasmi dan memusnahkan kekafiran. Sehingga berkat mereka, Islam yang semula tak dikenal menjadi tersohor dalam jalinan kekerabatan yang kental. Karena keperkasaan mereka hati musuh takut dan gelisah. Apakah bedanya anak domba dan si pemberani gagah. Siapa saja yang bersama Rasulullah peroleh kemenangan. Singa di rimba bila menemuinya akan diam gemetaran. Takkan kau lihat sahabat Nabi yang tak menang. Takkan ada musuh Nabi yang tak jadi pecundang ia tempatkan umatnya dalam benteng agamanya. Bagai singa yang tinggal di hutan bersama anaknya. Sering kali Al-Qur'an jatuhkan para pendebat. Sering kali dalil-dalil kalahkan musuh Muhammad. Cukup sebagai mukjizat, Nabi berilmu padahal buta huruf. Di zaman jahiliah, Nabi terdidik tanpa pengasuh.

\section{(Bagian 9) Tawassul Kepada Nabi Muhammad SAW}

Kupuji Nabi dengan pujian agar dosaku diampunkan. Karena umurku habis untuk bersyair dan pengabdian. Keduanya mengalungi dosa yang menakutkan seakan aku hewan sembelihan yang siap dikorbankan. Kuturuti godaan masa muda untuk bersyair dan mengabdi.

Tiada satu pun kudapat kecuali dosa dan sesal diri. Alangkah ruginya jiwaku dalam perniagaannya. Tak pernah membeli dan menawar agama dengan dunia. Barang siapa menjual akhirat untuk dunia sesaat. Jelas ia tertipu dalam setiap jual beli yang diakad. Jika kuperbuat dosa, janjiku pada Nabi tidaklah gugur. Juga tali hubunganku dengannya tidaklah terputus. Namaku juga Muhammad (Bushiri), jaminanku buat Nabi. Dialah sebaik baik manusia yang tepati janji. Jika kelak di akhirat, ia tak sudi menolongku. Maka alangkah rugi dan celakanya diriku. Tapi mustahil ia tolak para peminta syafaatnya. Atau peminta perlindungannya pulang dengan sia-sia. Semenjak kuwajibkan diriku untuk memberinya pujian. Kudapatkan Nabi sebaikbaik pemberi pertolongan. Pemberiannya tak luputkan seorang pun pemintanya. Karena hujan mengguyur bunga di bukit secara merata. Dengan pujian ini tidaklah kuinginkan gemerlap dunia. Seperti yang zuhair mula ketika ia puji Raja Har.

\section{Fadhilah Shalawat Burdah}

Burdah artinya mantel dan juga dikenal sebagai bur'ah yang berarti shifa (kesembuhan). Imam Bushiri adalah seorang penyair yang suka memuji-muji raja-raja untuk mendapatkan uang. Kemudian beliau tertimpa sakit faalij (setengah lumpuh) yang tak kunjung sembuh setelah berobat ke tabib manapun, tak lama kemudian beliau bermimpi bertemu Rasulullah SAW yang memerintahkan untuk menyusun syair yang memuji Rasulullah. Maka beliau mengarang syair burdah dalam 10 pasal. Pada tahun 6-7 $\mathrm{H}$, seusai menyusun syair burdah, beliau kembali bermimpi bertemu Rasullulah SAW yang menyelimutinya dengan burdah 
(mantel). Ketika bangun, sembuhlah beliau dari penyakit lumpuh yang dideritanya. Qosidah burdah ini tersebar di seluruh penjuru bumi dari timur hingga barat. Bahkan disyarahkan oleh sekitar 20 ulama, diantaranya yang terkenal adalah Imam Syabukhiti dan Imam Baijuri. Habib Husein bin Mohammad Alhabsiy (saudara Habib Ali Alhabsyi Sohibul Maulid Simtud Duror) biasa memimpin Dalail Khoiroot di Mekkah. Kemudian beliau mimpi bertemu Rasulullah SAW yang memerintahkannya untuk membaca burdah di majelis tersebut. Dalam mimpi tersebut, Rasulullah SAW bersabda bahwa membaca burdah sekali lebih afdol dari pada membaca dalail khoiroot 70 kali. Ketika Hadramaut tertimpa paceklik hingga banyak binatang buas berkeliaran di jalan, Habib Abdurrahman Al Masyhur memerintahkan setiap rumah untuk membaca burdah sehingga rumah-rumah mereka aman dari gangguan binatang buas.

Imam Bushiri mengatakan bahwa burdah ini sangat mujarab untuk mengabulkan hajat-hajat kita dengan izin Allah SWT. Namun terdapat syarat-syarat yang harus dipenuhi. yaitu istiqomah, mengulangi bait "maula ya solli wa sallim" berwudhu, menghadap kiblat, memahami makna bait-bait, dibaca dengan himmah yang besar, beradab, memakai wewangian.

\section{SIMPULAN}

Shalawat yang merupakan bentuk pengejawantahan dari rasa cinta seorang muslim terhadap Nabi Muhammad SAW. Dalam perkembangannya shalawat memiliki banyak ragam dan jenisnya, salah satunya yakni burdah. Shalawat Burdah merupakan syair puji-pujian yang ditujukan untuk Nabi
Muhammad SAW, pesan moral, nilai-nilai spiritual dan semangat perjuangan yang ditulis oleh seorang penyair bernama Abu Abdillah Syarafudin Abi Abdillah Muhammad Bin Khammad Ad-Dalashi Ash-Shanja AsySadzili Al-Bushiri yang kemudian dikenal dengan Imam Bushiri. Shalawat burdah terdiri dari 160 bait dan terbagi kedalam 10 bab pembahasan. Burdah memiliki arti mantel atau jubah yang dipakai oleh oleh bangsa Arab pada masa itu. Shalawat yang dikarang oleh Imam Bushiri dinamai dengan shalawat burdah karena setelah ia menyelesaikan syair shalawat ini ia bermimpi bertemu dengan Rasulullah SAW dan menyelimutinya dengan baju jubah milik Rasulullah SAW. Saat itu dia sedang dalam keadaan lumpuh namun setelah ia bermimpi seperti itu ia bangun dalam keadaan sembuh. Sehingga dengan adanya peristiwa itu terkenal shalawat itu dengan shalawat burdah. Shalawat burdah mempunyai lafaz-lafaz yang indah dan ungkapan teladan yang kaya akan nasihat, juga mengandung ajaran tentang keagungan, perangai dan watak.

Dengan bahasa yang begitu indah, Imam Al Bushiri telah berhasil menanamkan kecintaan dan kasih umat Islam kepada Nabi Muhammad SAW. Tema dan amanat yang terkandung dalam shalawat tersebut adalah mengajarkan agar manusia tidak tenggelam dalam cinta, tidak menuruti hawa nafsu serta tidak berbuat maksiat, beriman kepada Allah SWT. Serta berpegang teguh pada agama, mencintai Rasullullah SAW dan mencontoh perilakunya, mengajarkan agar manusia berpegang teguh pada Al-Qur'an, mengajarkan agar manusia berjihad dijalan Allah, mengajarkan agar manusia tidak berputus asa dan banyak membaca shalawat Nabi.

\section{DAFTAR PUSTAKA}

Adib, Muhammad. (2009). Burdah Antara Kasidah, Mistis Dan Sejarah. Yogjakarta: Pustaka Pesantren.

Atmazaki. (2005). Ilmu Sastra: Teori Dan Terapan. Padang: Angkasa Raya.

Baharun, Muhammad. (1996). Burdah Madah Rosul Dan Pesan Moral. Surabaya: Pustaka Progresif.

Daradjat, Zakiah. (1984). Dasar-Dasar Agama Islam. Jakarta: Bulan Bintang.

Poerwadarminta. (2007). Kamus Besar Bahasa Indonesia. Jakarta: P.N. Balai Pustaka. 